\title{
Development and Performance Evaluation of Corrosion Resistance Self-Healing Coating
}

\author{
Akshya Kumar Guin, Suryakanta Nayak, Manish Kumar Bhadu, \\ Veena Singh, and Tapan Kumar Rout \\ Research and Development, Tata Steel Ltd., Jamshedpur 831001, India \\ Correspondence should be addressed to Akshya Kumar Guin; akshya.guin@tatasteel.com
}

Received 6 February 2014; Accepted 25 March 2014; Published 23 April 2014

Academic Editors: M. Aparicio and A. Hermann

Copyright (C) 2014 Akshya Kumar Guin et al. This is an open access article distributed under the Creative Commons Attribution License, which permits unrestricted use, distribution, and reproduction in any medium, provided the original work is properly cited.

Polymer based nanocapsule was developed using core-cell approach, where the core material was methyl diphenyl diisocyanate and the cell material was urea-formaldehyde. The synthesized capsules of 100 to $800 \mathrm{~nm}$ size were incorporated into sol-gel matrix to prepare a final coating for steel protection. This coating was found protecting the steel at the damage or crack locations in $3.5 \%$ $\mathrm{NaCl}$ solution. SEM micrographs confirmed healing of the coating at the damage or crack points.

\section{Introduction}

Having been inspired by nature, coating designers are trying to convert the traditional coating into the "smart or intelligent" coating. Self-healing is one of the examples of smart coating [1]. When coatings get damaged in the form of cracks induced by mechanical, thermal, and chemical means, regardless of the application, the integrity of the structure is significantly compromised. Since the damage deep inside material is difficult to perceive and to repair in particular, the material would be motivating to have ability of selfrepairing through various stimuli response based on physical, chemical, mechanical, or thermal means which trigger the healing process. These progresses have now opened an age of new intelligent materials. Continuous efforts are made to mimic natural materials and to integrate self-repairing capability into polymers and polymer composites. Keeping all this in mind, self-healing concept has drawn considerable research interest in the last few years. Like pharmaceutical industry microcapsule technique is being used in corrosion prevention coatings. Healing is achieved by incorporating healing agents and a catalytic chemicals trigger within a polymer matrix. When coating is damaged by mishandling or misuse of the coated structure microcapsules rupture and active healing agent come out from the shell and with the help of catalyst healing the damage area.
In short, self-healing material provides the following advantages over the conventional coating:

(i) automatic repairing process;

(ii) barrier protection of underlying substrates;

(iii) autopreservation of aesthetics of surface appearance of coatings, plastic, and films;

(iv) restoration of mechanical integrity of load bearing materials as in composites [2-4].

Now researchers are focusing on the development of smart coatings, which are new generation functional coatings with mimicking nature. Self-healing coating is one of the examples of smart coating [5-7]. Conventional barrier protective coating when gets damaged during transportation or fabrication process, cracks or pin hole develops on the damaged area and localized corrosion initiates at that area and gradually propagates to other areas. These types of difficulties in repairing damaged area were well taken care of by scientists, by designing intelligent coatings using core-cell approach. The selection of a core material in a nanocapsule is important because this decides which stimuli response is needed to heal the damage. Self-healing concepts have drawn considerable research interest for pharmaceutical industries and in development of corrosion resistance coatings. When 
TABLE 1: Composition of self-healing coating.

\begin{tabular}{lcc}
\hline Sr. number & Ingredient & Composition by wt \% \\
\hline 1 & Titania-precursor & $60-63$ \\
2 & Coupling agent-methyl & $36-39$ \\
3 & hydrogen silicone & $0.5-2$ \\
4 & Nano capsule & 1 \\
\hline
\end{tabular}

coating is damaged by mishandling or misuse of the coated structure, microcapsules rupture and active healing agent come out from the core through the cell. The core material reacts with the catalyst either in the coating matrix or by moisture to heal the damaged area [8-12].

Present research work emphasized on the development of a methyl diphenyl diisocyanate based nanosize capsule and incorporation of nanocapsule and corrosion resistance pigments like nanolamellar zinc flake into a titania based solgel coating matrix to generate the self-healing and corrosion resistance coating on steel substrate (see Table 1).

\section{Experiment}

2.1. Preparation of Nanocapsules. Capsules were prepared by in situ polymerization in an oil-in-water emulsion as reported by White, Jinglei et al. [2], Trask et al. [3], and Blaiszik et al. [4]. At room temperature $\left(20-25^{\circ} \mathrm{C}\right), 5 \mathrm{~mL}$ of $5.0 \mathrm{wt} \%$ polyvinyl alcohol (PVA), urea, formaldehyde, and deionised water were mixed in a $250 \mathrm{~mL}$ three neck round bottomed flask connected to a reflux condenser and equipped with a mechanical stirrer. After the urea dissolved $\mathrm{pH}$ of the solution was adjusted to 3.5 by slow addition of $1 \mathrm{~N} \mathrm{NaOH}$ and the temperature was kept at $60-70^{\circ} \mathrm{C}$ for one hour and then ureaformaldehyde prepolymer solution was obtained.

Under agitation, a slow stream of methyl diphenyl diisocyanate was added to the prepared prepolymer solution to form an oil-in-water emulsion. The tapered $3.2 \mathrm{~mm}$ tip sonicator horn of a $750 \mathrm{~W}$ ultrasonicator was placed in the solution for 3 minutes at $40 \%$ intensity with continuous mixing at $2000 \mathrm{rpm}$ in room temperature. This sonication step changes the emulsion from slightly cloudy to opaque white. $12.67 \mathrm{~g}$ formalin (37\% formaldehyde) was then added to obtain a 1:1.9 molar ratio of formaldehyde to urea. The emulsion was covered and heated at a rate of $1^{\circ} \mathrm{C} / \mathrm{m}$ up to $55^{\circ} \mathrm{C}$. After $4 \mathrm{~h}$ of continuous agitation at $800-2000 \mathrm{rpm}$ the mixture was allowed to cool at ambient temperature. After cooling, the suspension was filtered by vacuum filtration method. The nanocapsules were properly rinsed with deionised water and air-dried for about $48 \mathrm{~h}$.

2.2. Coating Formulation. The titania sol was prepared by mixing Ti-isopropoxide and 2-methoxy glycol as outlined by our previous work [6, 7]. After $24 \mathrm{~h}$ of aging, N-phenyl3-aminopropyl triethoxy silane was added slowly into the titanium sol in $1: 1(\mathrm{~V} / \mathrm{V})$ mixing ratio at room temperature; this solution is treated as base sol-gel solution. Selfhealing coating formulation was prepared by incorporating previously synthesized $1 \%$ (by $\mathrm{W} / \mathrm{V}$ ) nanocapsules and $0.5 \%$ nanozinc-aluminium laminar alloy pigments (4:7 zinc to aluminium ratio by weight percentage, density is approximately $1.1 \mathrm{~kg} / \mathrm{L}$, and dimension is $20-50 \mathrm{~nm}$ dia and $10-15$ micron length) and $1 \%$ into the above sol-gel polymer matrix. The commercially available dispersing agent like BYK 3441 (1\% of total solid) was used for easy dispersion of pigments in sol-gel matrix. The cold rolled and annealed (CRCA) steel sheets were used for present study; these sheets were cleaned to remove oil and grease and subjected to phosphating in tricationic phosphate base solution to obtain a thin coating of $<0.5$ micron thickness $\left(2-3 \mathrm{gm} / \mathrm{m}^{2}\right)$. The synthesized sol was applied on the substrate by dipping process, where dipping time was $1 \mathrm{~min}$ at room temperature (RT), followed by drying at $150^{\circ} \mathrm{C}$ for 1 hour.

The probable reaction between titania precursor and coupling agent $\mathrm{N}$-phenyl-3-aminopropyl triethoxy silane is given below (Figure 1(a)).

2.3. Chemical Reaction in Nanocapsules Synthesis. Ureaformaldehyde based nanocapsules were synthesized as described in the experimental part. During the process, core chemicals like methyl diphenyl diisocyanate were covered with urea-formaldehyde (UF) resin. This reaction was carried out by in situ polymerization in an oil-in-water emulsion, where PVA is used as an emulsifying agent. The synthesis of nanocapsule in urea and formaldehyde backbone is a two-step process. First step is the methylation where formaldehyde reacts with urea, as shown in Figure 1. In the second step, the condensation reaction between the various methylol species and amines takes place. At low $\mathrm{pH}$, the produced UF resins cure irreversibly to form a cross-linked network and this reaction can be induced by addition of further ammonium chloride. Resorcinol was used to improve the cocondensation reaction products.

The core chemical of nanocapsule contains isocyanate group. During the initiation of any crack, this isocyanate group reacts with water and moisture present in atmosphere and heals the damaged area.

\section{Results and Discussion}

3.1. Nanocapsule Characterization. A series of characterisation tests were carried out for capsules to understand the capsules morphology, physical properties, and stability. Cell wall integrity, aggregation, and nanocapsule sizes were observed by scanning electron microscope (SEM).

3.1.1. Capsule Size Analysis. Capsule size analysis was performed by SEM; the capsule's size fall in a wide range of 20-250 micrometer without the application of ultrasonicator. Microcapsule sizes decrease extensively to an order of 200$800 \mathrm{~nm}$ by using ultrasonicator treatment for about $3 \mathrm{~min}$. The reason for this, is that the fluid flows away from the propeller, many large microeddies exist, and in the vicinity of the propeller blades many small microeddies exist, which results in a wide length scale. The capsule size can be controlled by adjusting the agitation rate. In the present study at $2000 \mathrm{rpm}$ with $3 \mathrm{~min}$ ultrasonicator, the average diameter of the prepared capsule is found to be $200-800 \mathrm{~nm}$. 
<smiles>CO[Si](C)(CCCCN(C)c1ccccc1)OC</smiles>

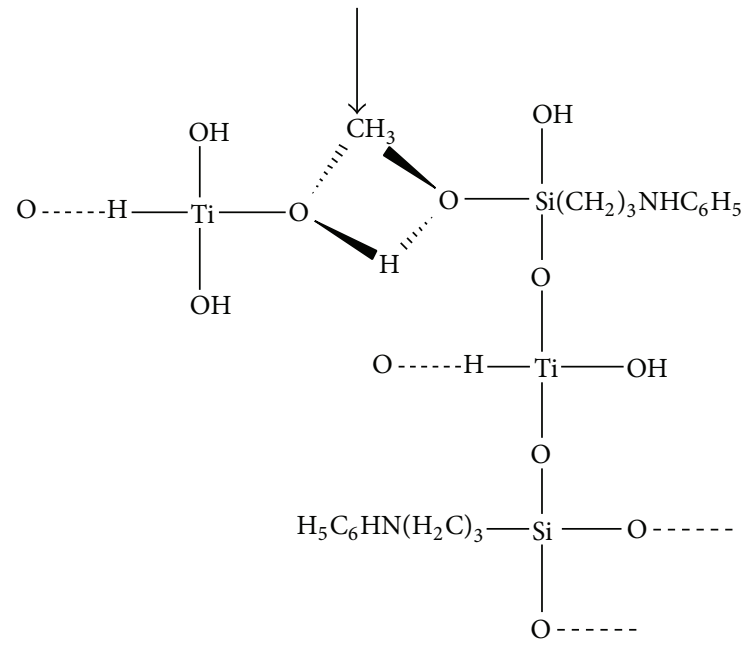

(a)

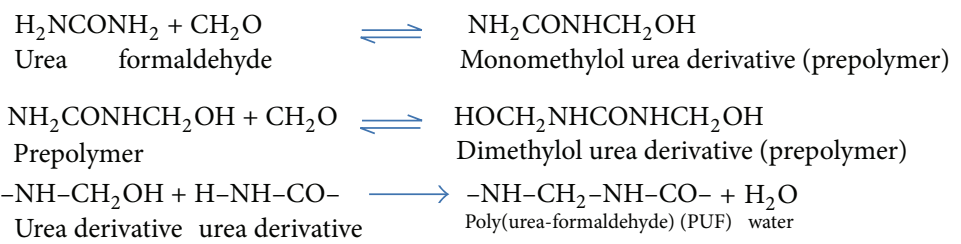

(b)

$$
\begin{aligned}
& -\mathrm{N}=\mathrm{C}=\mathrm{O}+\mathrm{H}_{2} \mathrm{O} \longrightarrow-\mathrm{NH}-\mathrm{CO}-\mathrm{NH}-+\mathrm{CO}_{2} \\
& -\mathrm{N}=\mathrm{C}=\mathrm{O}+\mathrm{HO}-\longrightarrow-\mathrm{NH}-\mathrm{CO}-\mathrm{O}^{-}
\end{aligned}
$$

(c)

FIGURE 1: (a) Probable reaction mechanism of Ti-sol and coupling agent. (b) Reaction scheme of the formation of U-F prepolymer and PUF. (c) Reaction scheme of isocyanate derivative with water.

3.1.2. Nanocapsule Surface Morphology. Figure 2 shows the SEM morphology of nanocapsule. It was observed that the shape of nanocapsule is spherical and the surface of nanocapsule is rough and shaggy. There is a possibility of uniform distribution of nanocapsules, which covered the substrate fully for better corrosion and self-healing property.

3.1.3. Thermal Resistance of Nanocapsules. The thermal stability of nanocapsules plays an important role in their application in self-healing composites. Figure 3 shows TGA diagram of nanocapsule with UF wall shell, weight loss near $100^{\circ} \mathrm{C}$ is mainly due to the removal of entrapped residual water, and the elimination of free formaldehyde. The weight loss at temperature between 200 and $300^{\circ} \mathrm{C}$ is mainly due to the decomposition of the PUF shell wall $[13,14]$. The residue undergoes extensive fragmentation near $400^{\circ} \mathrm{C}$ and the prepared nanocapsules have a good thermal stability.

3.1.4. Characterization of Nanocapsule by FTIR. It is seen from the FTIR spectra in Figure 4, of urea-formaldehyde coated nanocapsule, core chemical, and nanocapsule rupture with water, that all are matching at characteristic peaks of a $\mathrm{N}-\mathrm{H}$ vibration at $1571 \mathrm{~cm}^{-1}$ a $\mathrm{C}=\mathrm{O}$ stretching vibration at $1650 \mathrm{~cm}^{-1}$ and a C-H vibration at $1460 \mathrm{~cm}^{-1}$. C-N stretching

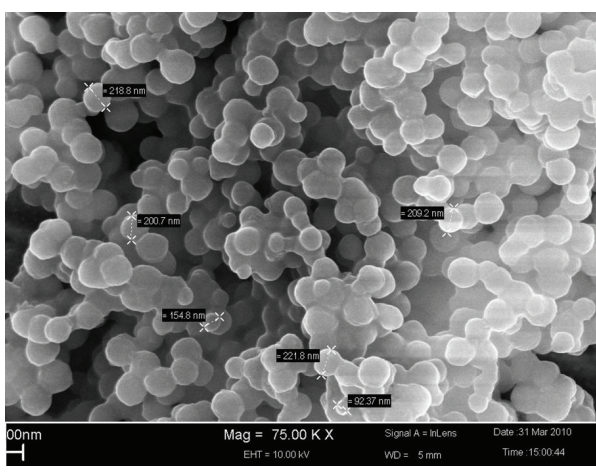

Figure 2: SEM image of microcapsule with 100-200 nm dia.

vibrations are shown at 1286 and $1142 \mathrm{~cm}^{-1}$. This spectrum confirms that the cell material is made of urea-formaldehyde polymer.

When the broken capsules are allowed to react with water it shows sharp absorption peaks at 1694 and $1562 \mathrm{~cm}^{-1}$, as shown in Figure 4, which represents the presence of urethane linkage only, which means that core materials are active 
TABLE 2: Salt spray test result.

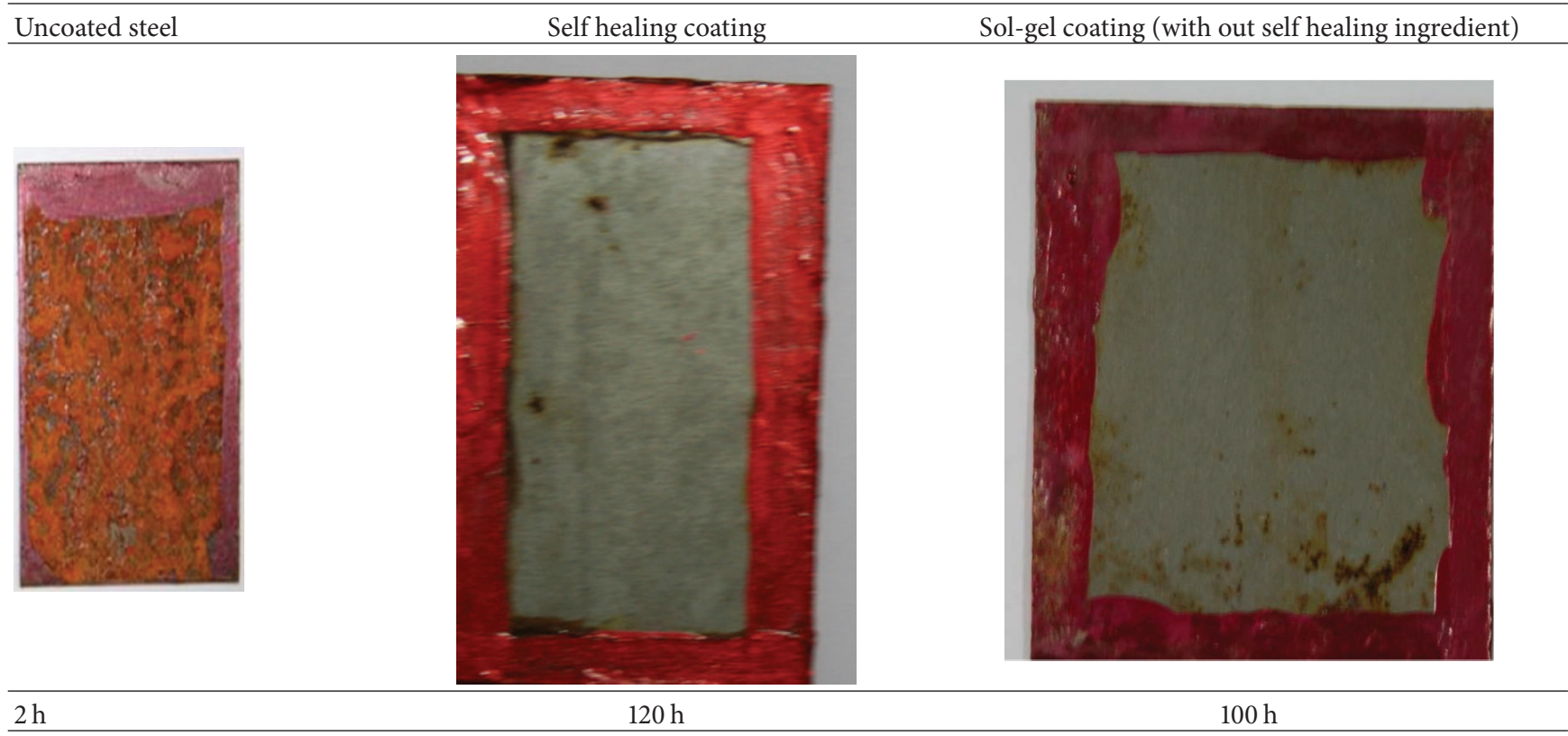

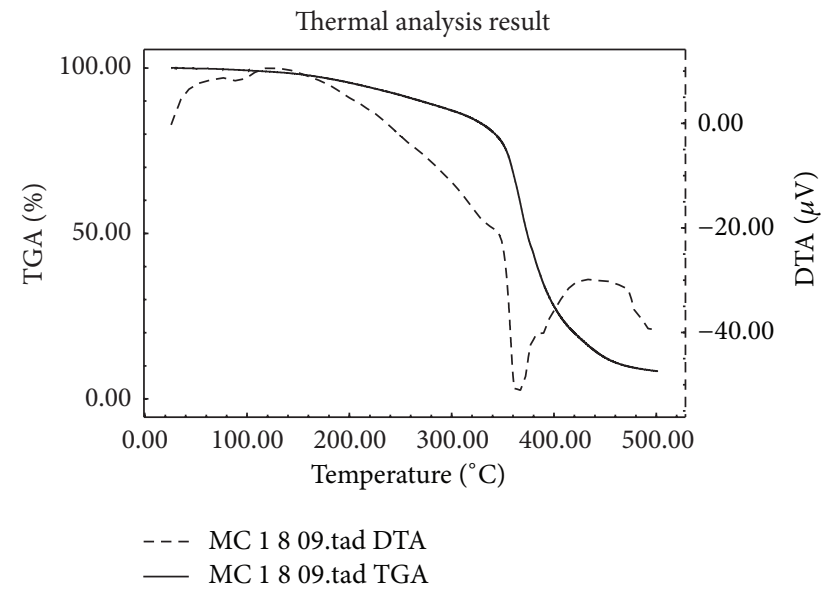

FIGURE 3: TGA-DTA graph of urethane capsule.

enough and are reacting with water to form a urethane linkage.

3.2. Self-Healing Ability. After successful preparation, the nanocapsule was embedded in a titania based polymer matrix for achieving self-healing ability. In the present study, $1 \%$ of prepared nanocapsules along with $0.5 \%$ zinc-aluminium laminar alloy pigments was incorporated in sol-gel matrix and the final coating solution was applied on steel surface. After seven days of aging at room temperature, coated panels were punctured and investigated for self-healing ability. Under this investigation, the punctured coated steel substrates were exposed in $3.5 \% \mathrm{NaCl}$ solution to check the propagation or healing of punctured area. SEM-EDX techniques were used for evaluation of self-healing property of coating. It was observed from the SEM-EDX analysis, as shown in Figure 5, that self-healing ability was observed within $8 \mathrm{~h}$ of damage.

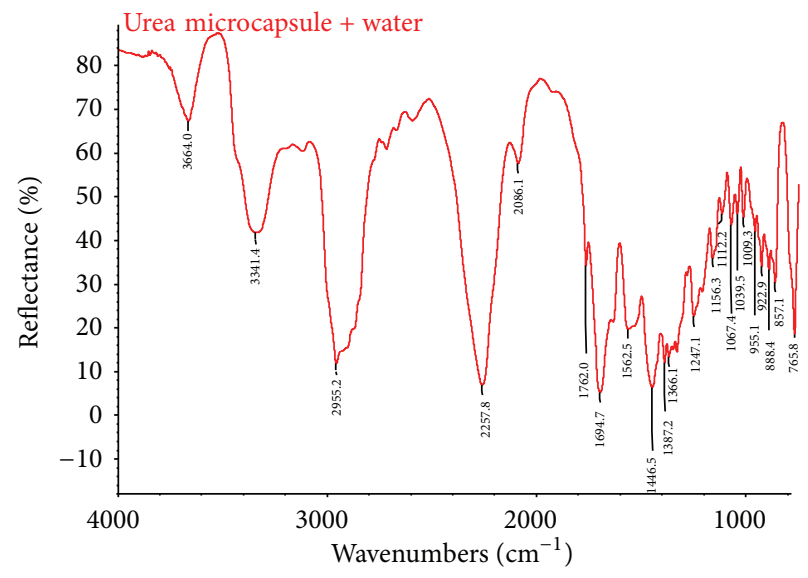

FIGURE 4: FTIR spectra of broken capsule in water.

Incorporation of nanozinc-aluminium lamellar pigment and nanocapsule enhanced the self-healing property of coated steel. SEM-EDX analysis confirmed the healing ability of coated sample by synergic effect of nanocapsule and zincaluminium alloy based sol-gel coating. This self-healing ability can be occurred by two ways; firstly, by the capillary flow of core chemical from the capsule rupture and subsequent interaction with moisture (as shown in Figure 1); secondly by the interaction of zinc-aluminium pigment with moisture, which leads to the formation of zinc and aluminium oxide on the scratch surface (as shown in SEM-EDX, Figure 5).

3.3. Corrosion Resistance Study by ASTM B 117 Salt Spray. Salt spray test was conducted to check the coating delamination and blister formation across the inscribed area of coated sample with 6-10 micron dry film thickness and the result is shown in Table 2. It was observed that, due to strong 


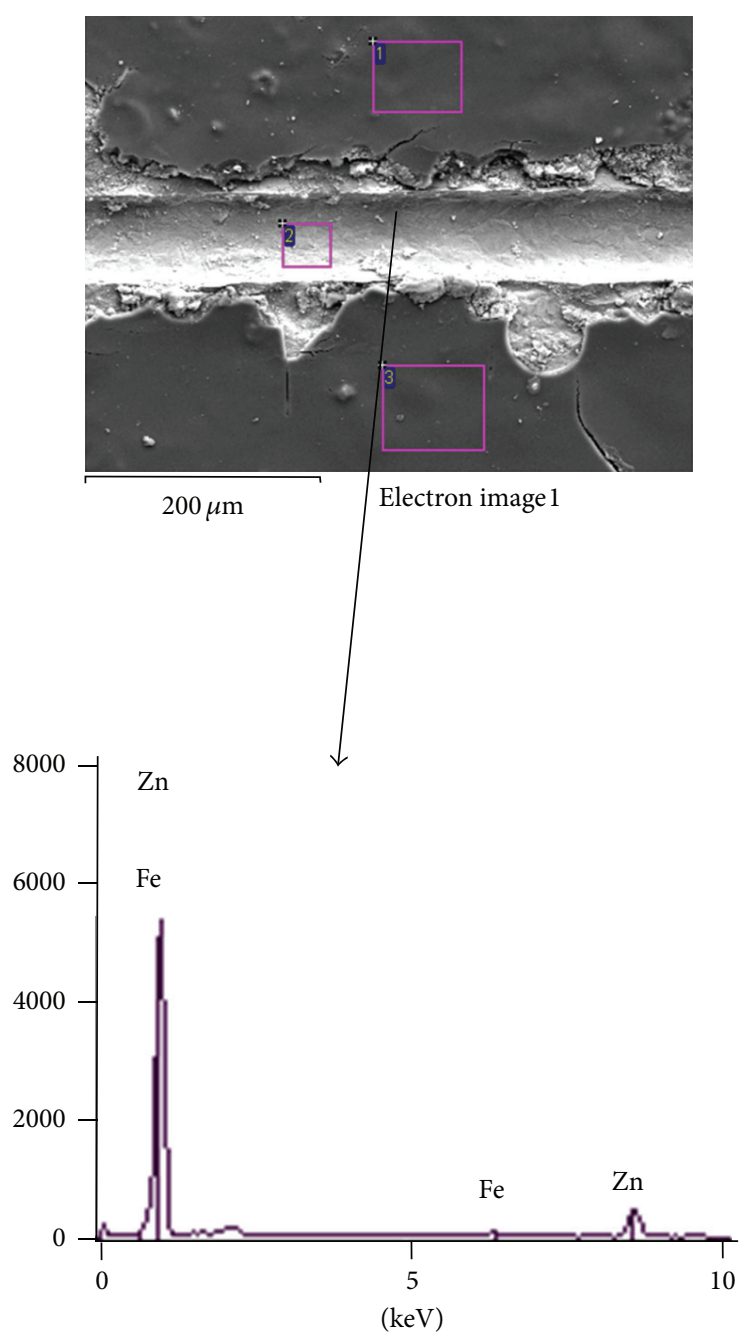

(a)

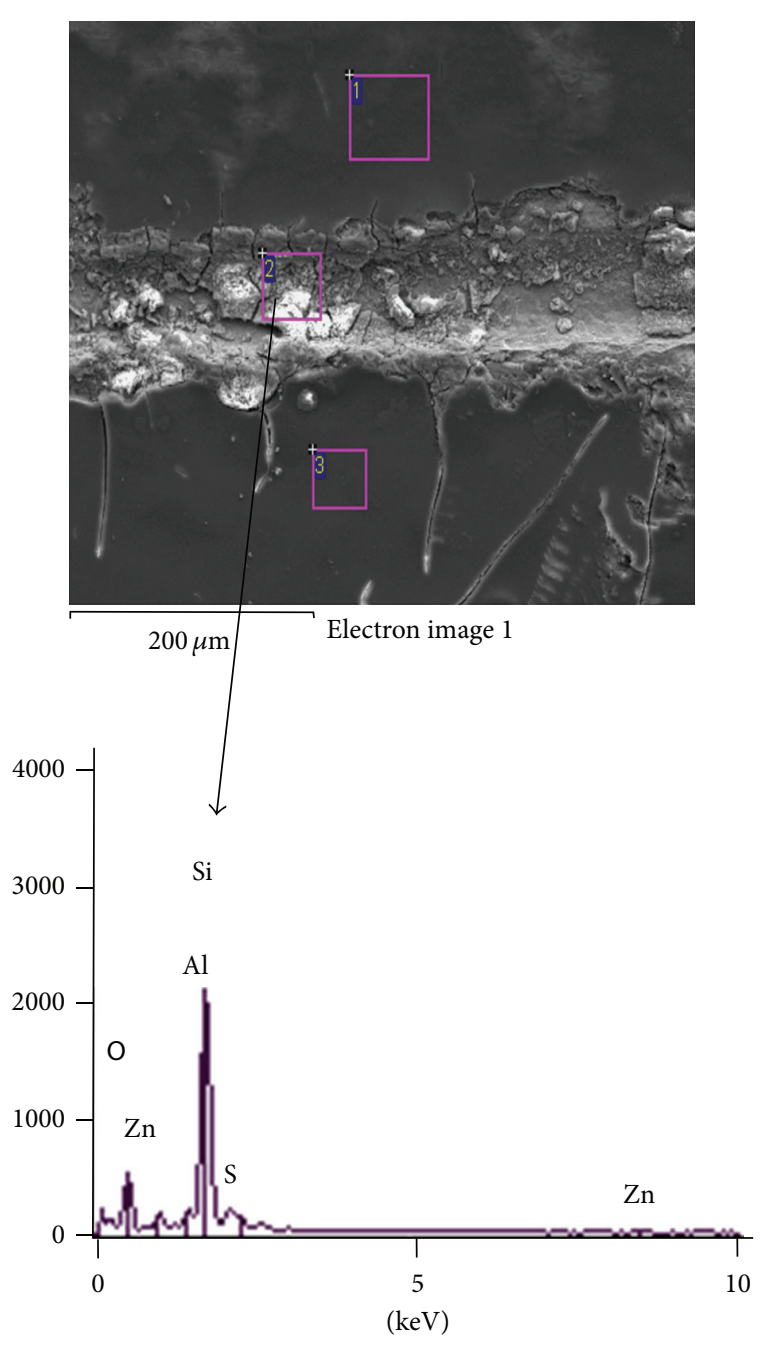

(b)

FIgURE 5: (a) SEM-EDX of initial cut sample. (b) SEM-EDX of self-healing coating after $8 \mathrm{~h}$ of cut.

adhesion of self-healing coating with steel surface, there was no trace of osmotic blister formation on coating surface, even after $100 \mathrm{~h}$ of exposed in salt spray chamber. After $120 \mathrm{~h}$ of exposure, coated panel developed medium size blister which was converted to dance blister after $150 \mathrm{~h}$. The coating showed good barrier and corrosion resistance properties as against uncoated steel sheet which corrode after $2 \mathrm{~h}$ of exposure in ASTM B 117 test chamber and $100 \mathrm{~h}$ for solgel coating without having any self-healing ingredients. The reasonable salt spray resistance of the developed coating might be due to the formation of bonds between polymer molecule and metallic surface and due to presence of laminar structure of Zn-aluminum nanopigment, diffusion of water, and other corrosive ingredients through polymer coating which was delayed. So penetrable damaging efficiency of localized corrosion was reduced by self-healing mechanism.

3.4. EIS Study. EIS is an excellent tool to study the mechanism and kinetics of the corrosion reaction. The change in impedance spectrum due to immersion in the corrosion environment helps to understand the protective ability of the developed coatings. The resistance obtained at low frequency region is crucial to explain the corrosion resistance performance and intactness of the coatings. In the present study, EIS study of coated samples was carried out between $100 \mathrm{kHz}$ and $0.01 \mathrm{~Hz}$ at the Ecorr. Figures 6(a)-6(e) show the EIS graph of coated samples at different intervals of time. The physical values were fitted with the VERSATEC software through appropriate equivalent circuit as shown in Figure 7. The system is assumed to consist of three interfaces with different resistance and capacitance characteristics. The first interface is between sol-gel coating and $\mathrm{NaCl}$ electrolyte. Second is the coating and metal substrate and the third is the metal surface where corrosion activity encounters. The spectra revelled three time constants, Rcoat-Qcoat, Rox-Qox, and Rct-Qdl, corresponding to resistance and capacitance of the sol-gel film, intermediate oxide layer, and double layer, respectively. Gradual reduction in Rcoat value with time indicated the attack of coating surface by chloride ions. 


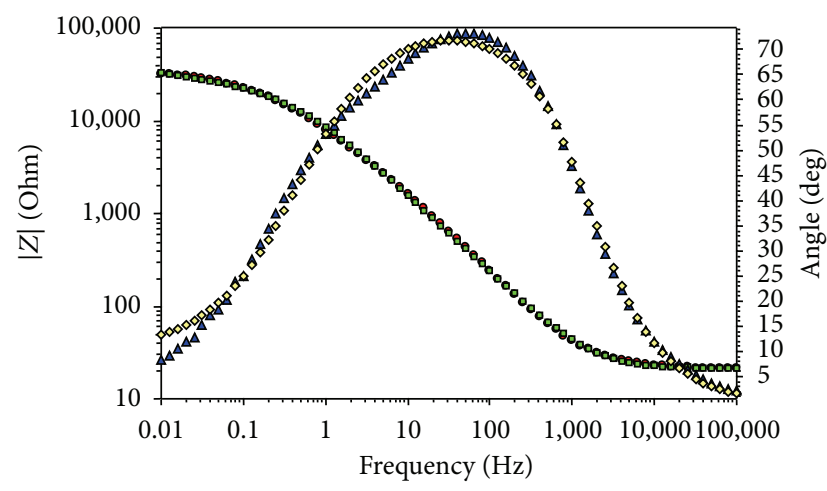

- $|Z|$, msd.

- $|Z|$, calc.

$\Delta$ Angle, msd.

$\diamond$ Angle, calc.

(a)

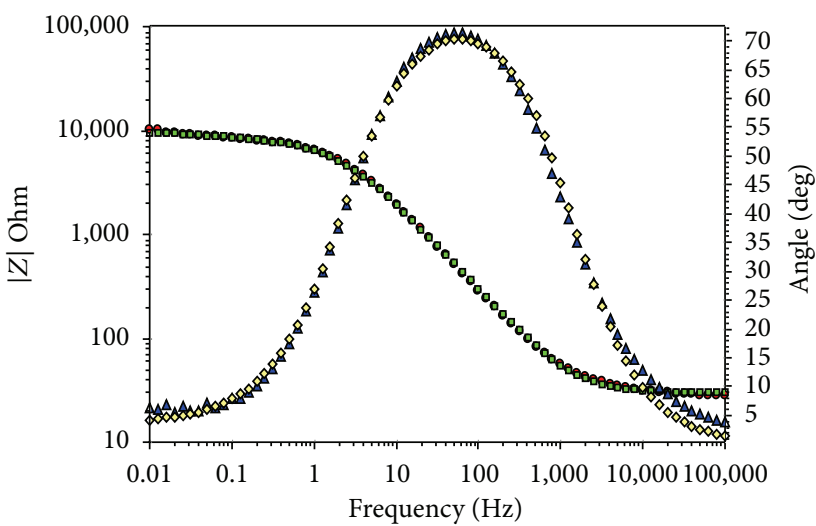

- $|Z|$, msd.

- $|Z|$, calc.
$\Delta$ Angle, msd.

$\diamond$ Angle, calc.

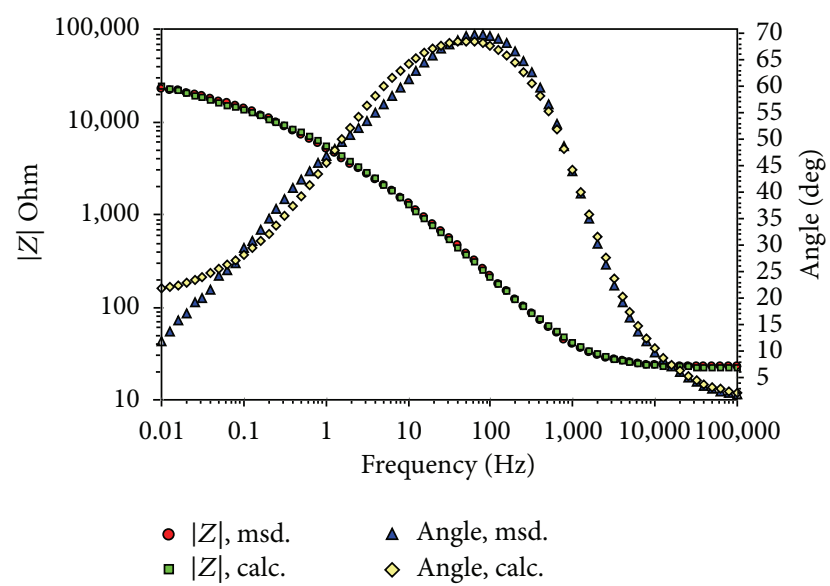

(b)

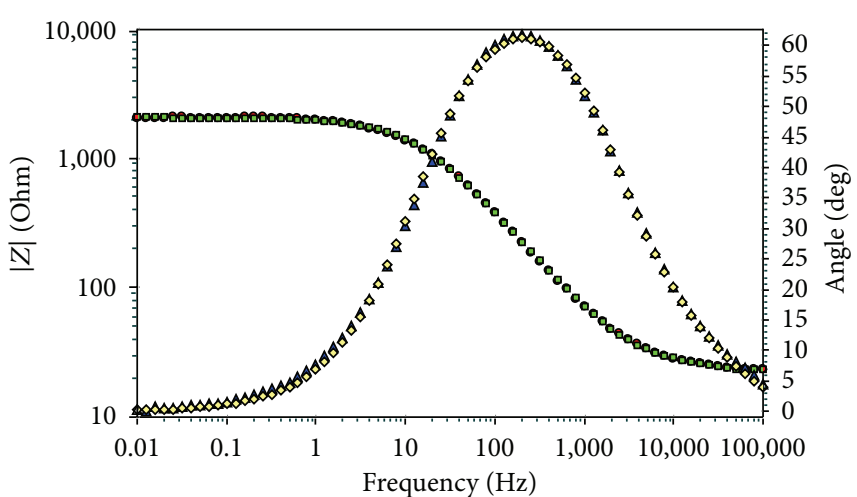

- $|Z|$, msd.

- $|Z|$, calc.
$\Delta$ Angle, msd.

$\diamond$ Angle, calc.

(c)

(d)

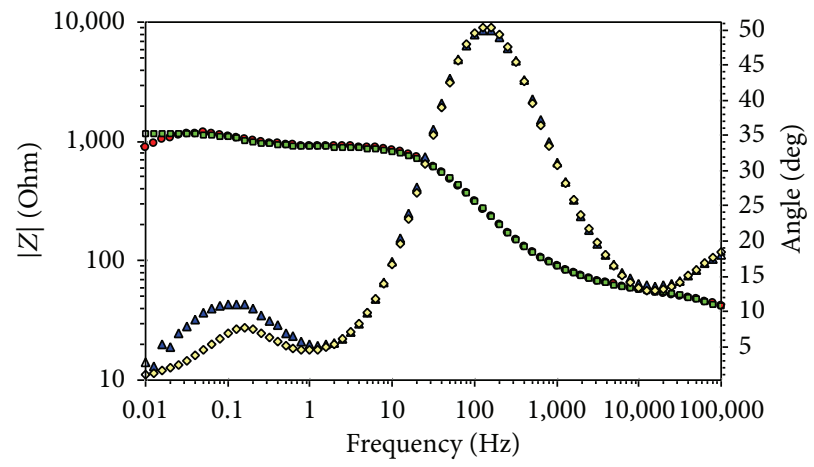

$\begin{array}{ll}-|Z|, \text { msd. } & \Delta \text { Angle, msd. } \\ \text { - }|Z| \text {, calc. } & \diamond \text { Angle, calc. }\end{array}$

(e)

FIGURE 6: (a) Initial EIS result of self-healing coated sample. (b) EIS result after $48 \mathrm{~h}$ of exposure of self-healing coated sample in $3.5 \% \mathrm{NaCl}$ solution. (c) EIS result after $96 \mathrm{~h}$ of exposure of self-healing coated sample in $3.5 \% \mathrm{NaCl}$ solution. (d) Initial EIS result of sol-gel coated sample (without any capsule). (e) EIS result after $96 \mathrm{~h}$ of exposure of sol-gel coated sample (without any capsule) in $3.5 \% \mathrm{NaCl}$ solution. 


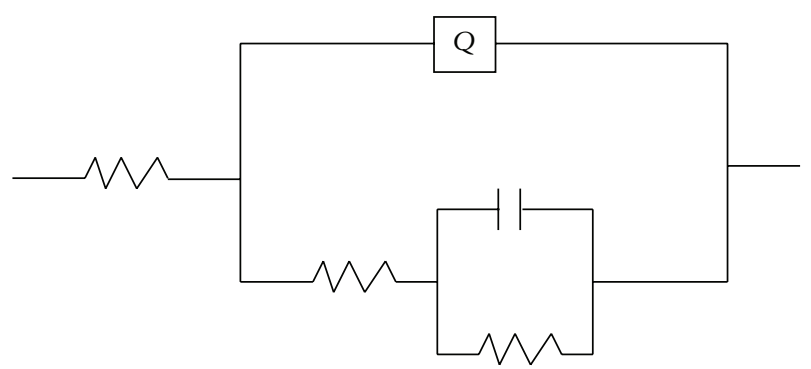

FIGURE 7: Curve fitting circuit of EIS diagram.

From the EIS graph, as shown in Figures 6(a)-6(e), it has been observed that sample coated with sol-gel based self-healing coating provides good barrier and corrosion resistance property than sample coated with only sol-gel solution (without self-healing capsule) in saline environment. This may be due to strong adhesion of coating with steel and uniform dispersion and coverage of nanocapsules in sol-gel coating. After $48 \mathrm{~h}$ of immersion, coating resistance decreased from $43625 \mathrm{ohm} / \mathrm{cm}^{2}$ to $24875 \mathrm{ohm} / \mathrm{cm}^{2}$, whereas corrosion resistance value dropped below $1000 \mathrm{ohm} / \mathrm{cm}^{2}$ for sample coated with only sol-gel solution containing no self-healing capsules. More interestingly there is no additional time constant observed even after $96 \mathrm{~h}$ immersion in $3.5 \% \mathrm{NaCl}$ solution and coating resistance was around $10823 \mathrm{ohm} / \mathrm{cm}^{2}$; this indicates that sample coated provides a good barrier protection and improves corrosion resistance of steel substrate.

\section{Conclusions}

Methyl diphenyl diisocyanate as core material containing nanosize capsules was prepared using an in situ UF encapsulation by sonication technique. The capsule was found active and remained thermally stable, till $200^{\circ} \mathrm{C}$. The nanocapsules and nanozinc-aluminium alloy pigments were successfully incorporated in sol-gel matrix, which provided uniformly coated self-healing coating. Healing effect observed within $8 \mathrm{~h}$ of damage was initiated using optical and SEM techniques. This nanocapsule and zinc-aluminium pigments embedded self-healing coating and enhanced corrosion resistance of coated steel.

\section{Conflict of Interests}

The authors declare that there is no conflict of interests regarding the publication of this paper.

\section{Acknowledgment}

The authors would like to thank the Management of Tata Steel Limited for the permission to publish and encouragement to carry out this work.

\section{References}

[1] S. K. Ghosh, T. Jana, R. Kumar, and B. Ray, "Self-healingcoating's perspective \& recent advances," Paints India, vol. 4, p. 85, 2010.

[2] Y. Jinglei, M. W. Keller, J. S. Moore, S. R. White, and N. R. Sottos, "Microencapsulation of isocyanates for self-healing polymers," Macromolecules, vol. 41, no. 24, pp. 9650-9655, 2008.

[3] R. S. Trask, G. J. Williams, and I. P. Bond, "Bioinspired selfhealing of advanced composite structures using hollow glass fibres," Journal of the Royal Society Interface, vol. 4, no. 13, pp. 362-371, 2007.

[4] B. J. Blaiszik, N. R. Sottos, and S. R. White, "Nanocapsules for self-healing materials," Composites Science and Technology, vol. 68, no. 3-4, pp. 978-986, 2008.

[5] V. Sauvant-Moynot, S. Gonzalez, and J. Kittel, "Self-healing coatings: an alternative route for anticorrosion protection," Progress in Organic Coatings, vol. 63, no. 3, pp. 307-315, 2008.

[6] A. K. Guin, S. Nayak, T. K. Rout, N. Bandyopadhyay, and D. K. Sengupta, "Corrosion resistance nano-hybrid sol-gel coating on steel sheet," ISIJ International, vol. 51, no. 3, pp. 435-440, 2011.

[7] A. Guin, S. K. Nayak, T. K. Rout et al., "Corrosion behavior of nanohybrid titania-silica composite coating on phosphated steel sheet," Journal of Coatings Technology and Research, vol. 9, no. 1, pp. 97-106, 2012.

[8] A. Kumar, L. D. Stephenson, and J. N. Murray, "Self-healing coatings for steel," Progress in Organic Coatings, vol. 55, no. 3, pp. 244-253, 2008.

[9] S. R. White, N. R. Sottos, P. H. Geubelle et al., "Autonomic healing of polymer composites," Nature, vol. 409, no. 6822, pp. 794-797, 2001.

[10] J. M. Kamphaus, J. D. Rule, J. S. Moore, N. R. Sottos, and S. R. White, "A new self-healing epoxy with tungsten (VI) chloride catalyst," Journal of the Royal Society Interface, vol. 5, no. 18, pp. 95-103, 2008.

[11] J. M. Kamphaus, J. D. Rule, J. S. Moore, N. R. Sottos, and S. R. White, "A new self-healing epoxy with tungsten (VI) chloride catalyst," Journal of the Royal Society Interface, vol. 5, no. 18, pp. 95-103, 2008.

[12] S. H. Cho, H. M. Anderson, S. R. White, N. R. Sottos, and P. V. Braun, "Polydimethylsiloxane-based self-healing materials," Advanced Materials, vol. 18, pp. 997-1000, 2006.

[13] X. He and X. Shi, "Self-repairing coating for corrosion protection of aluminum alloys," Progress in Organic Coatings, vol. 65, no. 1, pp. 37-43, 2009.

[14] S. V. Lamaka, M. L. Zheludkevich, K. A. Yasakau, R. Serra, S. K. Poznyak, and M. G. S. Ferreira, "Nanoporous titania interlayer as reservoir of corrosion inhibitors for coatings with self-healing ability," Progress in Organic Coatings, vol. 58, no. 23, pp. 127-135, 2007. 

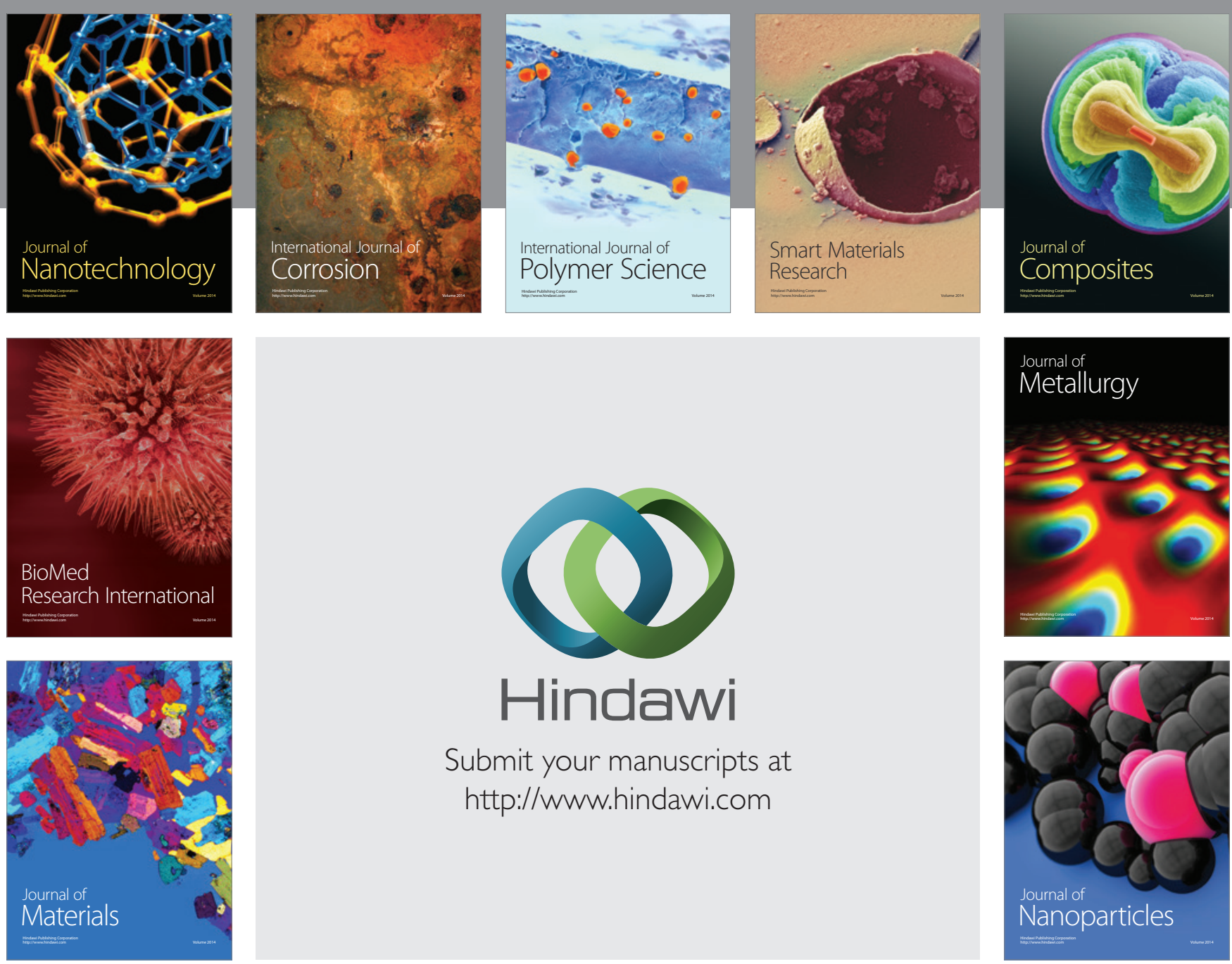

Submit your manuscripts at http://www.hindawi.com
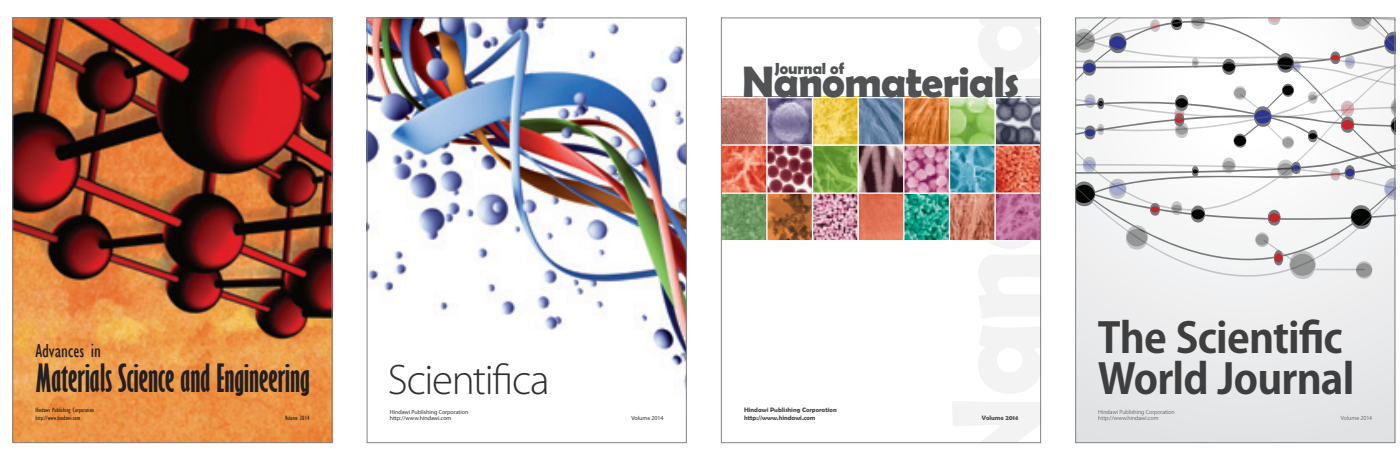

\section{The Scientific World Journal}
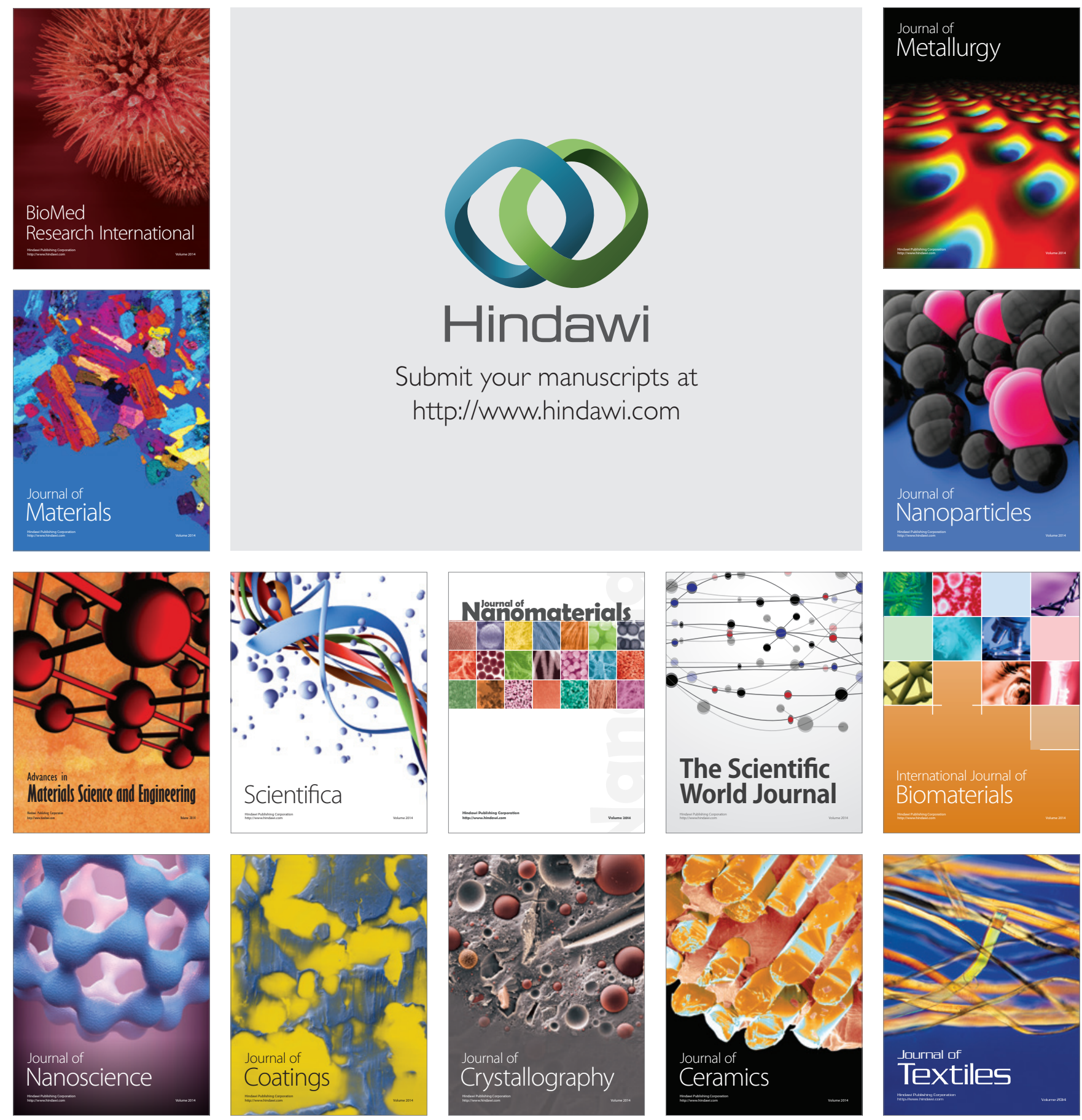